\title{
Research on Construction of Enterprise Information System under the Development of Computer Network Biao Wan ${ }^{1}$, Chunmei $\mathrm{Xu}^{2}$
}

${ }^{1}$ College of computer technology and software engineering, Wuhan Polytechnic, Wuhan, 430070, China

${ }^{2}$ College of humanities, Wuhan Polytechnic, Wuhan, 430070, China

Keywords: computer network technology, support, information system, construction, shortcoming

\begin{abstract}
At present, there still exist some problems in the construction of enterprise information system of China, which seriously prevents the development of Chinese enterprises. Aimed at the series of problems, a detailed research is conducted in this paper, and the corresponding improvement measures are given from the scientific planning of information system, expansion of information system construction space, participation of government, information security and the construction of human resources etc., and it is hoped to give a reference for the construction of enterprise information system under the development of computer network in the realistic life.

With the continuous development and evolution of information technology, information system has been more and more widely used in the enterprise. Information system itself has the convenient function, sharing function and online transmission function, bringing many conveniences for the development of enterprises. Relying on this information system, enterprises can publicize their product externally, and make enterprises enhance the cognition to enterprise products, so as to improve the purchase probability. In addition, the enterprise information system also can enhance the application ability of enterprise e-commerce technology. In the current society where the marketization and informatization have been strengthened increasingly, to remain invincible, enterprises must have an information release, retrieval and management system[1]. Only with this system can the enterprise competitiveness be strengthened.
\end{abstract}

\section{Significance of information system to improve enterprise competitiveness}

With the rapid development of economic globalization and the coming of knowledge economy, information technology has become a key factor concerning the development of enterprises, whether an enterprise can obtain advantages in the fierce market competition depends on the power of information technology. Information plays an import role in the prosperity and decline in an enterprise, under the context of market economy, those who master information will have the initiative in the market. In the computer network, the information system constructed is a magic power to promote the development of enterprises. Therefore, to become large and strong, an enterprise must strengthen the construction of enterprise information system[1].

(I) Continuously enhance brand effect

An enterprise can enhance its contact and communication with the outside world by establishing its own internal information network system, many enterprises have very a small brand popularity because they have just built their brands, while the construction of information system can improve the publicity effect of brand and fully play the role of brand. On one hand, it is beneficial for the effective operation of enterprises, and on the other hand, it is able to publicize the image of enterprises, make enterprise expand their influence, spread their own characteristic culture and manifest their extraordinary strength.

(II) Deal with the relation with customers

No enterprise can be inseparable from the support of customers, more and more precise customer enterprises will be more beneficial for the growth of enterprises. Therefore, to have their products widely recognized, the enterprises should strengthen the communication with customers, deal with each question raised by the customers. With its strong information transmission function, 
information system can establish a customer service department within the enterprise and answer the questions raised by the enterprises, which is an important means to deal with the relation between enterprises and customers, and plays an irreplaceable role in the expansion of market in a certain extent.

(III) Continuously promote the process of e-commerce development

With the development of modern economy, e-commerce has become an important marketing mode currently. At present, many large companies adopt this marketing means to continuously enhance their own economic strength. The achievement of marketing with e-commerce more highlights the important role of information system, because the transaction under the e-commerce platform is achieved by network, and cash transfer and transaction can be realized through network[2]. In addition, the perfection and update of some functions in the enterprise information system can promote the perfection and development of e-commerce technology. The e-commerce under the information carrying provides business scope for the enterprise development and wins more market shares.

(IV) It is able to improve the enterprise management

Generally the information system provides the users with services mainly in two aspects, the first is the service within the enterprises, and the second is the service outside enterprises. The external service mainly includes the transaction and negotiation between enterprises and the external customers and the marketing plan and industrial meeting, which can improve the commercial negotiation. The internal service mainly refers to the establishment of information communication website within the enterprise, which can achieve the information sharing and transmission; the establishment of automatic office system makes enterprises achieve the automatic office work and improve the working efficiency.

(V) Adapt to the demand of current situation of information economy development

In the new situation, the nature of enterprise competition is the competition of talents. Developing and retaining talents is an important trend for the development of enterprises currently. Information technology is a reflection of knowledge economy, and the role of talents under the knowledge economy is very important. There are many professional talents in enterprises, like the talents with strong business ability and professional technical application, information technology application talents and management talents etc. Under the new situation of information technology, the informatization construction of enterprises can cultivate a group of information management talents, so as to promote the stable and sustainable development of the enterprises[3].

\section{Shortcomings of construction of enterprise information system}

At present, many enterprises have been rapidly developed with the support of the local government, and similarly, the construction of information system has also been enhanced significantly, and the effect and the benefit improvement brought by information system are obvious. However, in the process of development, some risks and problems have also been highlighted gradually, the existence of these problems will inevitably generate adverse influence on the construction of information system and even the development of the whole enterprise. The specific problems are explained as follows:

(I) The rules for construction of information are unclear

The construction of enterprise information system is a complicated process, while ensuring the normal operation, it is also required to improve the management of the system in various aspects. Many enterprises cannot effectively combine the technological application, system establishment, operation means and marketing plan when constructing the information system and cannot establish a feasible design plan for the construction of enterprise information system. The rule for the construction of enterprise information system is very unclear, and the blind construction will only add unnecessary trouble to the future work. The means are not so clear, and the technical conditions are also not combined with the system conditions, hardware conditions and software conditions[4], In the whole process, many enterprise managers are lack of certain far sight, only emphasize the near-term work, but ignore the long-term development in the future. 
(II) The economic and hardware investment is insufficient

Many enterprises can realize the important role of establishing information system to their own development, but in view that it is required to invest a lot of funds and technologies before the construction of information system, which will influence the enterprise income, and the daily maintenance and repair need funds, so many enterprises are unwilling to take this adventure, let alone investing funds. Besides, some small enterprises also have such problems, due to poor financing, there is no large investment in enterprises, causing that there is a serious lack of investment in funds and equipment, which restrict the process of information construction in a certain extent. In addition, for consideration of cost, many enterprises reduce the purchase of equipment, the lack of hardware configuration causes it is unable to smoothly carry out system information, which finally directly influences the obtaining of reasonable benefit and prevents the further development of enterprises.

(III) No emphasis on enterprise system

Many businesses in the enterprises should be restricted through management, while the most effective method to achieve management is to construct an effective system. The establishment of system under the information system should be reflected in the management of operation and production methods. Therefore, with the development of times, in the construction of modern enterprise information system, it is required to reform and innovate the system continuously. In the modern enterprise management, even if new technologies and new products are introduced, but if there is a lack of system, the use of equipment might not conform to the standards, which will influence the normal running of information system.

(V) Lack of talents

With the coming of the times of knowledge economy, the competition of talents among enterprises will be inevitably enhanced, many enterprises are extremely strict in recruitment, and the phenomenon of paying more attention to academic background but less to ability are frequent, obviously, the high threshold in recruitment directly causes the serious shortage of talents reserves of enterprises. Another situation is that many professional talents are not from the professional training class. After recruitment, the enterprises will train them, and they will be allocated to each post after qualified training, they are not so familiar with some theoretical knowledge, and their occupation quality is also to be improved. In addition, some talents have very strong professional ability, but they are lack of communication with leaders and colleagues. Furthermore, there is a lack of overall consideration for the system maintenance, and it is unable to start from the actual condition of enterprises, which will inevitably influence the use effect of system. As stated above, talents are the base and root for an industrial to survive and develop, and according to the current situation, the problems existing in the use of personnel will become a main factor to prevent the development of enterprises if not improved accordingly.

\section{Methods to promote construction of enterprise information system}

These problems in the enterprises above are very common, which will influence the information construction of enterprises if not solved timely. Therefore, it is required to propose the corresponding solutions to relevant problems on this basis, specifically, the enterprise information system can be constructed from the following aspects:

(I) Scientifically plan the information system construction in combination with the actual condition of enterprises

Many enterprises are different in development level, productivity, marketing means and staff allocation, therefore, when constructing the information system, it is also required to consider these problems and they cannot be generalized. When constructing the information system, enterprises should count the number of personnel, scale and work nature of each department first. If there are a few persons in the department and the demand for application of information system is not very strong, the focus of construction can be put on the departments with strong information system demand, in this way, it is possible to more reasonably allocate the resources, without waste. 
(II) Take advantage of e-commerce platform

As a product under the development of important information system, e-commerce has become a main technology leading the economic development in continuous development. Enterprises can analyze and refer to the R\&D and running characteristics of enterprises in detail, so as to provide references for the information construction. Besides, enterprises can also improve the application of e-commerce technology while constructing the information system effectively.

(II) Strengthen government guidance and supervision functions

Enterprises can provide support of fund, technology and policy for the enterprises and in the construction of enterprise information system, the government can help enterprises establish the information statistics system conforming to their own development, so as to regulate the trade operation of enterprises; the enterprises can establish an information disclosure system, so the construction of various information systems can meet various standards and functions of the government. The enterprises can correspond to the requirements of the government in policy by continuously improving the online office system, taking more advantage of information system to achieve automatic office work and make the office work means conform to the legal provisions[5].

(IV) Improve information system security

With the continuous update and development of information technology, information security has become the key to smooth carry out the information system. Many information systems are not so good in the maintenance of security, to achieve smooth operation, the enterprise information system should eliminate various potential dangers. At present, the factors threatening the information security include internet virus and hacking etc. Facing these security threats, enterprises should regularly inspect the information system after construction and pay attention to the establishment of technical prevention system; besides, enterprises should divide various internal information, and for some particularly confidential information, it is possible to take the targeted preventive measures. Finally, it is required to strengthen the use of authentic software, which can improve the security of information system in the source.

(V) Improve development of human resources

As mentioned above, talents are the important force for the development of enterprises, and even the main force to determine and promote the future development of enterprise. Therefore, in this way, another important influential factor of information system construction is the absorption of various talents and the effective training and management. In the enterprise management, the department of talents is the HR department, so the HR department should cooperate with enterprises to continuously improve the profession and occupation quality of the personnel and strengthen the training of personnel lack of technical ability, continuously cultivate comprehensive talents with business ability, management ability and technical application ability for the enterprises, continuously improve the personnel utilization and create an appropriate talent work and development environment in the enterprises.

\section{Conclusion}

In recent years, China has rapidly developed its economy and has gradually ranked among the great powers in the world, but compared with the developed countries, there still exists some gaps. Therefore, we must pay attention to our shortcomings, firmly grasp the pulse of information times, reform and innovate the modern enterprises and continuously improve the backward components in the enterprise operation and management. So it is required to construct the enterprise information system on the basis of computer network. This does not represent that the enterprises keep pace with the times, but also adapts to the demands of continuous development of the enterprises. Therefore, the realization of effective information system construction strategy is of important theoretical value and practical significance.

\section{References:}

[1] Zhang Daohao, Research and Practice of Experimental Teaching of Course "Computer Network 
Technology [J], Journal of Anqing Normal University (natural science edition), 2009 (02)

[2] Liu Xuezhen, Development of Computer Cluster System Integrating High-speed Simulation Calculation and Real-time Visualization [A] Coordinative Development of Science \&Technology, Engineering, Economy and Society-Paper Collection of the $5^{\text {th }}$ Youth Academic Annual Conference of Chinese Association of Science and Technology [C], 2004

[3] Wan Lihong, Gao Huijun, Research on Application of Computer Network Technology in Urban Geographical Information System [A] Paper Collection of the $3^{\text {rd }}$ Yangtze River Delta Science \&Technology Formula (mapping branch) and 2006 Jiangsu Mapping Annual Conference [C], 2006 [4] Cui Yubao, Li Weihong, Yang Lijuan, Construction of Autonomous Course Learning Model based on Computer Network Technology [J] Modern Education Equipment of China, 2008 (01)

[5] Zhong Rilin, Ye Kun, Application and Design of Real-time Database in Distributed Radio and TV Monitoring and Dispatching Command System [A] Guangxi Society of Computer Paper of Collection in 2007 [C], 2007 